\title{
Opra's pragmatic approach to wind-ups - One year on
}

Received: 8th August, 2003

\section{Fiona Frobisher}

is a team leader for the Wind-Up Team at Opra. The team regulates all aspects of schemes in wind-up, including examining the need for compliance with the Pensions Act 1995 and supervising the winding up of schemes required to report under s. 72A of the Act. The Occupational Pension Regulatory Authority (Opra) is the UK regulator of work-based pensions. It aims to secure the best achievable protection for members of work-based pension schemes; promote high standards in the running of work-based pension schemes; and improve understanding of key issues in pensions regulation.

\begin{abstract}
This paper sets out the Occupational Pensions Regulatory Authority's (Opra's) current regulatory approach for dealing with schemes in wind-up and the common problems we have identified for schemes winding up. This concentrates on, but is not exclusive to, schemes due to report under the Pensions Act 1995, s. 72A. It considers the reasons for a new pragmatic risk-focused approach and the numbers of schemes in the current reporting tranches. Problems and common stumbling blocks identified in scheme wind-ups and Opra's regulatory approach to these areas are discussed. Two case studies are included.
\end{abstract}

Keywords: occupational pensions; winding up; Opra

\section{Drivers for a more pragmatic approach}

On 1st April, 2002, the Occupational Pension Schemes (Winding Up Notices and Reports etc) Regulations 2002 (The Regulations) came into force affecting schemes in wind-up. The new legislation gave the Occupational Pensions Regulatory Authority (Opra) a role in supervising these schemes. ${ }^{1}$ This was a new area of work for the authority and an opportunity to move away from a compliance-based approach, to considering in a much wider fashion what action can be taken to protect members' funds and support trustees.

The implementation of the Regulations coincided with a year of reviews of Opra's regulation of work-based pension schemes. Alan Pickering's report, 'A Simpler Way to
Better Pensions', ${ }^{2}$ suggested that the sector needed a 'new kind of regulator'. The National Audit Office produced a report on Opra in November 2002, ${ }^{4}$ which suggested that Opra should 'build on its achievements by focussing more closely on the risks to members of pensions schemes'. ${ }^{5}$ The last report of the year, Opra's quinquennial review was published in December. ${ }^{6}$ Whilst finding that Opra had generally performed well within the limitations of its powers, it supported Pickering's recommendation for a new kind of regulator and suggested that a change in the law was needed to enable Opra to focus on the greatest risks to pension schemes. ${ }^{7}$

In its first five years Opra has built up a picture of levels of compliance and risk in occupational pension schemes. As it moves to a risk-based approach, its aim is to: 
- secure the best achievable protection for members of work-based pension schemes;

- promote high standards in the running of work-based pension schemes;

- improve understanding of key issues in pensions regulation.

The new wind-up legislation was introduced as part of an overall government aim to reduce the length of time it takes to wind up a scheme 'facilitating' the wind-up. ${ }^{8}$ The speed up of wind-up is only one factor in ensuring that members receive the maximum amount of benefit due to them. When looking at reports about schemes in wind-up a pragmatic, risk-focused approach tailored to each scheme is taken.

\section{Problems for wind-ups}

The Regulations are being phased in on the basis of an 'oldest first' principle. Regulation 9 sets out the phasing in of reporting requirements. Unsurprisingly, many of the problems, with these schemes are historical - some current schemes have been winding up for over ten years. There are common problems of poor record keeping, lack of coordination and inadequate communication between parties involved in running the scheme, such as the trustees, administrators and advisers. Consequently much of Opra's current focus is directed at:

- supporting trustees to take ownership of the process and drive it forward;

- ensuring all parties are actively involved in drawing up a timetable to complete the wind-up;

- negotiating with and influencing parties where communication is breaking down.
Table 1: Phasing in of reporting requirements

\begin{tabular}{ll}
\hline Date of wind-up & Due to report by \\
\hline pre: $01 / 01 / 1990$ & $01 / 06 / 2002$ \\
$01 / 01 / 1990-31 / 12 / 1992$ & $01 / 04 / 2003$ \\
$01 / 01 / 1993-31 / 12 / 1995$ & $01 / 04 / 2004$ \\
$01 / 01 / 1996-31 / 12 / 1998$ & $01 / 04 / 2005$ \\
$10 / 10 / 1999-21 / 03 / 2003$ & $01 / 04 / 2006$ \\
\hline
\end{tabular}

Opra's supervision acts as a catalyst to inject urgency into slow moribund wind-ups, and has had positive responses from trustees and others.

If more flexible legislation is introduced, Opra intends to spend more time investigating schemes and asking for action in the areas identified as key risks and priorities for protecting members' benefits. While much of its focus is on schemes which fall into the current reporting tranches, where there are particular problems with schemes which fall outside these, it is still able to investigate and take action to facilitate these wind-ups as well.

\section{Case study 1}

\section{Background}

The scheme is a wholly-insured defined benefit scheme with 21 members. It commenced winding up on 31st October, 1990. The trustees are individual employees of the on-going principal employer, a college, who undertake the role as part of their job. They are unfamiliar with the mechanics of winding up a pension scheme and rely heavily on advisers.

\section{Opra's involvement}

In March 2002, Opra received a complaint from the trustees' advisers that the provision of information from the insurer had been poor. Opra asked for examples and then contacted both parties 
Table 2: Number of schemes in wind up (by reporting tranche)

\begin{tabular}{llc}
\hline Date of wind-up & Due to report by & Number of schemes \\
\hline pre: $01 / 01 / 1990$ & $01 / 06 / 2002$ & 3,900 \\
$01 / 01 / 1990-31 / 12 / 1992$ & $01 / 04 / 2003$ & 5,400 \\
$01 / 01 / 1993-31 / 12 / 1995$ & $01 / 04 / 2004$ & 4,500 \\
$01 / 01 / 1996-31 / 12 / 1998$ & $01 / 04 / 2005$ & 11,700 \\
$01 / 01 / 1999-21 / 03 / 2002$ & $01 / 04 / 2006$ & 4,500 \\
\hline
\end{tabular}

to express its concern about the situation. It sought to ensure that correspondence was dealt with more quickly to allow matters to move forward. The insurer was slow in dealing with Opra's requests for information and was warned about its powers to direct them to take action. However, the focus was to persuade the insurer that it was in its interests to work closely with the trustees to complete the wind-up.

There was no single factor which had caused this wind-up to take over 12 years, but without focus and ownership, the process had drifted. Opra encouraged all parties to agree to a timetable setting out the tasks to be achieved in a realistic time frame.

Further delays were caused when the college shut over the summer, during which time the trustees were not contactable and took no action on the wind-up. The trustees were warned that this was unacceptable. They supplied Opra and the other parties with alternative addresses so that progress could continue to be made.

Under Opra's supervision, the trustees, their advisers and the insurer now have a close cooperative relationship. They are making steady headway in winding up this scheme, without a direction being imposed on any party.

\section{The numbers of schemes in wind-up}

Before the legislation was introduced requiring reports from schemes in wind-up, research with various providers was undertaken to estimate how many schemes currently in wind-up fell into each tranche. The findings are estimated in Table 2.

So far, Opra has received 183 valid reports in the first tranche and 185 in second tranche. It had always been assumed that many of the schemes which had been in wind-up for some time would be money-purchase schemes, where the corporate trustees had disappeared when the company went into liquidation. It was decided that Opra would liaise directly with the providers to identify these orphan schemes. This has identified nearly 2,000 further schemes that should have been reported in the first tranche. Opra continues to collaborate with the insurers to ensure the wind-up of these schemes is completed. Not all insurers adopt the same approach. For example:

- some have contacted Opra to appoint their own corporate trustee bodies to batches of schemes to effect their wind-up;

- some are settling benefits with members directly, including buying s. 32 policies;

- some have approached Opra to appoint the members to secure their own benefits.

Ideally all schemes would appoint trustees. However in many cases, where schemes are fully insured and the appointment of an independent trustee would reduce 
members' benefits, the best and most pragmatic solution is for the insurers to settle benefits directly. In this situation, Opra asks for reports on a regular basis and if problems do occur, there is always the option to appoint a trustee.

Even taking into account the numbers of orphan schemes, it is clear that the numbers of schemes in the first tranche are substantially fewer than estimated. There appear to be two reasons for this. First, Opra does not generally expect Executive Pension Plans (EPPs) to report, where rules state that they 'may' enter wind-up when contributions cease. Given the nature of these schemes, in particular the fact that they are fully insured, it does not believe that extended wind-up presents a risk to members' benefits. Some of these schemes may have been counted in the original estimates. However, more significantly, it appears that the new legislation has been something of a catalyst for many insurers who have been taking action on inactive schemes. The last year has seen providers increasing the resources they give to schemes in wind-up, appointing project managers and in some cases outsourcing the task of winding up their schemes.

\section{Opra update on wind-ups}

Opra's work with schemes in wind-up has already identified areas which can be common stumbling blocks, such as:

- minimum funding requirement (MFR) valuations;

— investment issues;

— s. 75 debt;

- cash equivalent transfer values (CETVs);

- guaranteed minimum pension (GMP) equalisation.

Opra is preparing a detailed update on these and other areas, which should be available by the time this paper goes to print. Please contact Opra or check its website www.opra.gov.uk. Opra's current approach to some of these areas is summarised below.

\section{MFR, debt and investment}

Where a triennial MFR valuation reveals a deficit for an on-going scheme with a solvent employer, a new schedule of contributions will be prepared to make up this deficit. ${ }^{9}$ Once a scheme enters formal wind-up the schedule of contributions will no longer remain in force and any deficit will have to be made up by enforcing a debt on the employer using the provisions of the Pensions Act 1995, s. 75.

In most cases the calculation of a s. 75 debt will be the most important actuarial valuation for a scheme in wind-up and Opra will not normally insist on the continuation of regular triennial MFR valuations. Circumstances in which the need for an MFR valuation will arise cannot be ruled out but this is anticipated as being a rare occurrence.

In situations where Opra is approached by trustees or actuaries about their intention not to produce an MFR valuation further information about funding relating to calculation and pursuit of s. 75 debt; investment strategies; and provision of cash equivalent transfer values, is required.

Opra's concern is that members receive the maximum amount of pension available to them. When deciding whether to calculate and pursue a s. 75 deficit trustees are expected to consider:

- whether the employer is willing to meet at least part of the s. 75 deficit willingly;

- if the employer is insolvent, whether the likely recovery of any debt 
outweighs the costs involved in the calculation;

- the likelihood of securing payment of the debt.

To maximise the amount of money in the pension fund, trustees should ensure that careful consideration is given to the management of investments once wind-up has commenced. Trustees should take immediate investment advice addressing issues such as a gilt-matching policy and the implications this has for MFR and s. 75 deficit calculations.

\section{Cash equivalent transfer values (CETVs)}

There are several provisions in regulations which will allow trustees of schemes in wind-up to reduce CETVs to reflect the funding position of the scheme. ${ }^{10}$ However, in the initial stages of a wind-up the trustees may have difficulty in determining an appropriate amount for a transfer value due to uncertainty about the assets and liabilities of the scheme and the costs that winding up will incur.

Opra will not seek to penalise trustees who decide not to issue statements of entitlement during this time of uncertainty. However it expects trustees to:

- take actuarial advice before reaching this decision;

- consider an investment policy which may have an effect on transfer values;

- take steps to clarify assets and liabilities;

- make plans to enable themselves to quote transfer values at the earliest opportunity in the wind-up.

\section{Guaranteed minimum pension (GMP) equalisation}

GMP equalisation still remains a topic of concern for many trustees and their advisers and there are many differences of opinion on this issue. Opra's view is that there is no clear obligation on trustees to equalise benefits where inequalities arise only from the impact of the contracting-out legislation. In the course of regulating the winding up of schemes and through our research we have found that the majority of trustees adopt a pragmatic approach to this issue.

Opra is are aware of the wide variety of approaches taken and does not endorse one particular method. With help from their professional advisers, trustees can arrive at a solution that is suitable for their scheme. In reaching a decision trustees will need to:

- consider the options open to them;

- decide whether or not to equalise and, if so, how to equalise;

- take account of the specific circumstances of their pension scheme;

- bear in mind the practical requirements for securing the benefits with insurers;

- look carefully at the funding position of their scheme and at the costs to the fund of equalising benefits;

- consider whether the cost and time involved in devising and implementing a methodology for equalisation will outweigh the value in terms of benefit to members.

Failing to make a decision in relation to GMP equalisation is neither risk nor cost free. Opra's concern is to see that members' interests are protected. Although there is legal uncertainty in this area, in many cases differences in benefits caused by differences in GMPs are not significant. Trustees are advised against incurring delay, and potentially significant legal costs, in referring this issue to the courts. 


\section{Case study 2}

\section{Background}

The scheme is a wholly insured defined benefit contracted out scheme with close to 3,000 members. The trustee is a corporate trustee. The insurer had outsourced administration of the scheme which commenced winding up in April 1985 .

\section{Opra's involvement}

Opra received a full report from the trustee which outlined the steps that had been taken and the difficulties that had been faced in winding up the scheme, including evidence of significant difficulties and a strained relationship between the insurer and administrator.

The trustee also provided a detailed timetable for the winding up, which they had agreed with the scheme actuary. Opra was concerned that the insurer and administrator did not appear to have been involved in the creation of the timetable and that many of the deadlines set for the tasks were unrealistic.

Opra made contact with all parties to raise their concerns, and explained that it would supervise the winding up of the scheme and take a firm stance to ensure that all parties cooperated in the endeavour. The insurer and administrator explained to the trustee that the proposed timetable did not include all the tasks that they needed to perform to complete the wind-up. It became clear that neither party understood the other's objectives and constraints. Written negotiations were facilitated between all parties which provided a much clearer insight into the scheme's needs. A deadline was set for the timetable to be agreed so that the negotiations were concluded swiftly.
Opra has encouraged regular face-to-face discussions between parties to foster good relations. With a clear schedule for the wind-up in place, and commitment and cooperation from all parties Opra has now hightened supervision requiring only regular updates and re-negotiation of the schedule in the face of unexpected delays.

\section{Changes announced on 11th June, 2003}

One of the most important factors in Opra's pragmatic approach is that it is continually evolving to reflect the changes in the legislative and funding landscape, new concerns as they arise and its own experience of regulating schemes. Dialogue with interested parties is welcomed to inform them of its approach.

The government has announced changes in the regulation of pensions and new provisions for work-based pensions in 'Simplicity, security and choice: Working and saving for retirement. Action on occupational pensions'. ${ }^{11}$ In particular two of the provisions that have an impact on wind-ups are currently concerning trustees — the changing of funding basis to full buy-out where a solvent employer winds up an underfunded defined benefit scheme; and changing the priority order for settling liabilities. In the case of the full buy-out, draft regulations show that this provision would apply to schemes that enter wind-up on or after the 11th June, 2003. At the time of writing, draft regulations for the priority order changes have not been written. Some trustees are worried by this, but delaying wind-up because of future changes is contrary to the government's intention to speed up the process of winding up. Until the regulations are laid Opra believes that it is reasonable for trustees to proceed 
under current legislation and apply the priority order as currently set out. ${ }^{12}$

\section{References}

1 Pensions Act 1995, s. 72A.

2 'A Simpler Way to Better Pensions' DWP, 11th July, 2002.

3 Ibid., 1.17 A new kind of regulator. p. 5.

4 Opra: Tackling the risks to pension scheme members. Report by Comptroller and Auditor general. Published 6th November, 2002.

5 NAO press notice 63/02. 6th November, 2002.
6 Report of the quinquennial review of Opra by Brian Davis, Independent Reviewer, DWP, 17th December, 2002.

7 Ibid., Recommendations p. 7.

8 Pensions Act 1995, s. 72B.

9 Pensions Act 1995, s. 58. The Occupational Pension Schemes (Minimum Funding Requirement and Actuarial Valuations) Regulations 1996, reg. 15.

10 The Occupational Pension Schemes (Deficiency on Winding Up etc.) Regulations 1996.

11 'Working and saving for retirement: Action on occupational pensions', DWP, 11th June, 2003.

12 Pensions Act 1995, s. 73. The Occupational Pension Schemes (Winding Up) Regulations 1996, reg. 3. 